\title{
Electrochemical activity of heavy metal oxides in the process of chloride induced corrosion of steel reinforcement
}

\author{
V ŽIVICA \\ Institute of Construction and Architecture of the Slovak Academy of Sciences, Dúbravská cesta 9, 84220 Bratislava, \\ Slovak Republic
}

MS received 2 February 2002

\begin{abstract}
The influence of heavy metal oxides on the chloride induced corrosion of steel reinforcement in concrete was studied. Significant inhibition and stimulation of chloride induced corrosion have been observed. Basicity and acidity of the relevant metal ions, and their ability to form complexes are considered as the main factors of the observed effects.
\end{abstract}

Keywords. Heavy metal; oxides; chloride; corrosion; steel; concrete; reinforcement.

\section{Introduction}

Numerous chemical admixtures, both organic and inorganic, are able to cause or inhibit the corrosion of reinforcement in concrete. Moreover some of them may cause some side effects such as the retardation of the setting time of cement and the influencing of the engineering properties of concrete at a later state of hardening (Boyd and Tripler 1988). From a practical view point, the interesting group of admixtures represents inhibitors of corrosion. Among them inorganic inhibitors are potassium dichromates, stannous chloride, zinc and lead chromates, calcium hypophosfite, sodium and calcium nitrites. Organic inhibitors represent sodium benzoate, etylaniline, and mercaptobenzthiazole (Craig and Wood 1970; Rosenberg et al 1993).

It has been reported that oxides of zinc, copper and lead may act as inhibitors of chloride induced corrosion. On the contrary some heavy metal oxides like manganese and chromium oxides may stimulate this type of corrosion (Tashiro et al 1979, 1985; Tashiro 1984). It shows that inhibition effect of heavy metal oxides is not their universal property.

The mentioned electrochemical behaviour of heavy metal oxides $\left(\mathrm{MeO}_{x}\right)$ in the process of chloride induced corrosion is an interesting topic from two view points: (i) possibility of the utilization of the inhibitive effect of $\mathrm{MeO}_{x}$ as an admixture in reinforced concrete structures which will be exposed to the action of chloride environment, and (ii) evaluation of the long-term durability of the cement-based materials used as a stabilization matrix for wastes containing $\mathrm{MeO}_{x}$, when the danger of chloride induced corrosion is interesting.
The results of the study on the influence of admixture of various $\mathrm{MeO}_{x}$ on the chloride induced corrosion of steel are presented here.

\section{Experimental}

The mortar test prisms of $20 \times 20 \times 80 \mathrm{~mm}$ with the embedded $1 \times 3 \times 60 \mathrm{~mm}$ steel sticks were used for the study. The composition of the mortar mixture used was cement : sand ratio $1: 3$, w/c $0 \cdot 5$, with the addition of $4 \%$ $\mathrm{CaCl}_{2}$ and $1 \% \mathrm{MeO}_{x}$ by weight of the cement. For comparison, the mortar mixture with the addition of only $\mathrm{CaCl}_{2}$ were prepared. The prepared test specimens were cured at a temperature of $20^{\circ} \mathrm{C}$ and a relative humidity of $95 \%$. After 90 days of curing, the test specimens were crushed and the state of steel sticks were evaluated visually and their corroded area was estimated. An efficiency coefficient was introduced. It was given by the ratio of the corroded area (corr. $A_{\mathrm{CM}}$ ) of the sticks in the mortar with the addition of $\mathrm{MeO}_{x}$ and $\mathrm{CaCl}_{2}$ and of the corroded area of the sticks in the mortar with the addition of only $\mathrm{CaCl}_{2}\left(\operatorname{corr} . A_{\mathrm{C}}\right)$ :

$$
\mathrm{EC}=\frac{\operatorname{corr} . A_{\mathrm{CM}}}{\operatorname{corr} . A_{\mathrm{C}}} .
$$

According to this equation, the $\mathrm{MeO}_{x}$ showing the EC values $<1$ may be considered for the inhibitors, and those with the values of over 1 for the substances stimulating the chloride induced corrosion.

For the preparation of mortar mixture, materials used were: Portland cement CEM/42.5 according to the standard STN ENV 197-1, silica sand according to the standard STN 72 1208, chemically pure calcium chloride, and oxides, $\mathrm{Cr}_{2} \mathrm{O}_{3}, \mathrm{CuO}, \mathrm{MoO}_{3}, \mathrm{PbO}, \mathrm{TiO}_{2}, \mathrm{~V}_{2} \mathrm{O}_{5}, \mathrm{ZnO}$, 
$\mathrm{WO}_{3}$, and $\mathrm{ZrO}_{2}$. The used steel sticks were prepared from steel sheet class 11373 according to the standard STN 41 1373.

\section{Results and discussion}

The evaluation of the effects of $\mathrm{MeO}_{x}$ added on the chloride induced corrosion according to (1) is given in table 1 and shown in figure 1.

The results show that from the view point of influencing the chloride induced corrosion studied, $\mathrm{MeO}_{x}$ were entirely different substances.

In view of the given effects of $\mathrm{MeO}_{x}$, the mechanism of inhibition and stimulation effects, and their dependence on the $\mathrm{MeO}_{x}$ kind are interesting.

On the basis of the knowledge of mechanism of passivation of reinforcement in concrete and its chloride induced corrosion, these factors as the conditions of the $\mathrm{MeO}_{x}$ effects may be taken into consideration:

(i) Formation of a protective film on the surface of the steel formed by the reaction products of $\mathrm{MeO}_{x}$ and components of pore solution in the embedding concrete. This process as an inhibitive effect may be shown. A contingent binding of chloride in the formed reaction products to the inhibition of corrosion may contribute by decreasing of the disposable quantity of chloride for the chloride induced corrosion.

(ii) Decrease of $\mathrm{pH}$ value, and increase of electrical conductivity of pore solution. In principle the same effects as at the action of acidic environment on the reinforced concrete take place. An example may be the corrosion caused by air atmosphere containing aggressive $\mathrm{CO}_{2}, \mathrm{SO}_{2}$ and $\mathrm{NO}_{X}$. Therefore, in the presence of the effect of decrease of $\mathrm{pH}$ value by $\mathrm{MeO}_{x}$, a synergism of acidic and chloride induced corrosion may be expected. This as an intensification of the resulting corrosion may be observed.

Naturally the explanation of the principle of inhibition and stimulation of chloride induced corrosion by $\mathrm{MeO}_{x}$ is

Table 1. Evaluation of the effects of $\mathrm{MeO}_{x}$ addition on the chloride induced corrosion of steel.

\begin{tabular}{|c|c|c|}
\hline $\begin{array}{l}\mathrm{MeO}_{x} \text { added (in } \\
\text { brackets EC values) }\end{array}$ & $\begin{array}{l}\text { EC values } \\
\text { extent }\end{array}$ & $\begin{array}{l}\text { Characterization of the } \\
\text { electrochemical effect }\end{array}$ \\
\hline $\begin{array}{l}\mathrm{PbO}(0.08) \\
\mathrm{CuO}(0 \cdot 42)\end{array}$ & less than 1 & inhibition \\
\hline $\begin{array}{l}\mathrm{ZnO}(1 \cdot 04) \\
\mathrm{ZrO}_{2}(1 \cdot 04)\end{array}$ & from 1 to $1 \cdot 1$ & indifferent \\
\hline $\begin{array}{l}\mathrm{Cr}_{2} \mathrm{O}_{3}(1 \cdot 13) \\
\mathrm{V}_{2} \mathrm{O}_{5}(1 \cdot 57) \\
\mathrm{TiO}_{2}(1 \cdot 89) \\
\mathrm{MoO}_{3}(1 \cdot 89)\end{array}$ & from 1.1 to 1.9 & stimulation \\
\hline $\begin{array}{l}\mathrm{WO}_{3} \text { steel sticks } \\
\text { desintegrated totally }\end{array}$ & undefined & $\begin{array}{l}\text { extreme strong } \\
\text { stimulation }\end{array}$ \\
\hline
\end{tabular}

interesting. This enables the evaluation of the chemical properties of the studied $\mathrm{MeO}_{x}$ or their metal ions (Remy 1961).

\subsection{Inhibiting or indifferent $\mathrm{MeO}_{x}-\mathrm{PbO}, \mathrm{CuO}, \mathrm{ZnO}_{2}$ and $\mathrm{ZrO}_{2}$}

Their ions are of basic character having positive valency of 2 and they are able to form complex compositions. Evidently their presence in concrete due to their basicity do not decrease the level of $\mathrm{pH}$ of pore solution. It is a possible effect, but insufficient in the presence of the chloride induced corrosion. Therefore, probably the effect of formation of complexes on the surface of steel represents the protective barrier moderating the chloride attack which conditions the observed inhibitive effect. The similar mechanism like at the inhibition by known nitrite inhibitors may be assumed. In this case, ferrous ions produced in anodic process of corrosion are changed to the passive layer formed by $\mathrm{Fe}_{2} \mathrm{O}_{3}$ and $\gamma$-FeOOH. Thus, the passive chemical reaction of nitrite with ferrous ions is to block active corrosion centres by producing a passive ferric oxide protective film. Then iron in the ferric state does not formate complexes with chloride and chloride induced corrosion is then reduced (Gaidis and Rosenberg 1979; Diamond 1986; Dreeman et al 1991).

\subsection{Stimulating $\mathrm{MeO}_{x}-\mathrm{Cr}_{2} \mathrm{O}_{3}, \mathrm{~V}_{2} \mathrm{O}_{5}, \mathrm{TiO}_{2}$ and $\mathrm{WO}_{3}$}

The metal ions of these oxides show high levels of the valency reaching the value of 6 , moreover are of acidic character. Therefore, the presence of these oxides in concrete is able to decrease the $\mathrm{pH}$ of pore solution with the effects occurring at the action of acidic media on the reinforced structures.

According to the results obtained inhibition effects may show $\mathrm{MeO}_{x}$ with Me ions having positive valency 2,

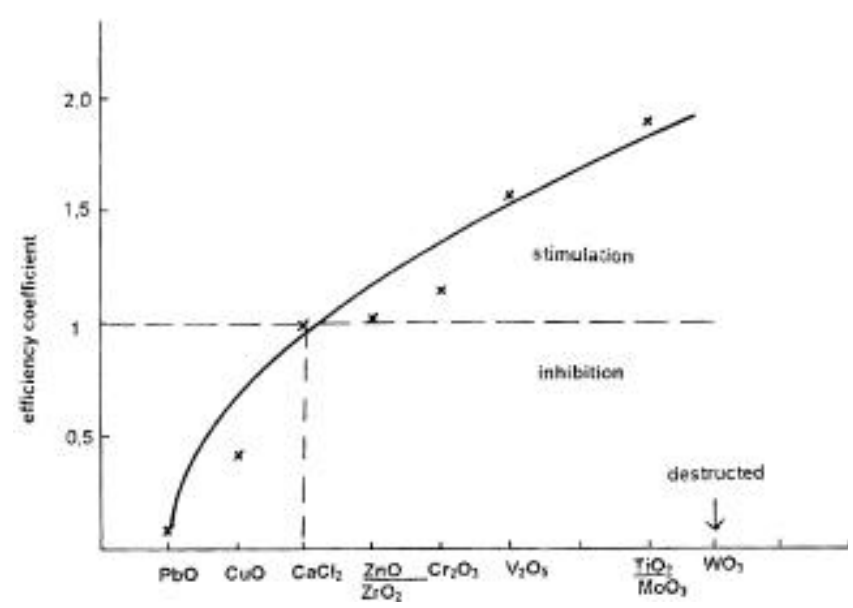

Figure 1. Dependence of the effect of heavy metal oxides added on the intensity of chloride induced corrosion. 
with basic character and able to form stable complexes. Probably the same effect may show ions of hafnium, thorium, and cadmium. Stimulation effect may show the ions of acidic character with higher degrees of valency like niobium, tantalum, protactinium, and uranium. However, an experimental verification of this assumption is needed.

\section{Conclusion}

The observed inhibition and stimulation effects of the heavy metals studied on the chloride induced corrosion of steel needs further detailed examination aimed at the composition of pore solution, its electrochemical properties, and the reaction products formed. That study is useful and needed for the reliable utilization of the shown inhibition effect of heavy metal oxides, and the evaluation of their influence on the engineering properties of cement based materials used as a stabilization matrix of the environmentally adverse wastes containing heavy metal composition.

\section{Acknowledgement}

The author wishes to thank the Slovak Grant Agency VEGA (grant 2/7003/22) for its support.

\section{References}

Berke N S and Weil T G 1992 World-wide review of corrosion inhibitors in concrete, In Advances in concrete technology (ed.) V M Malhotra (Canada: CANMET) pp 889-924
Boyd W K and Tripler A 1988 Mater. Protect. 740

Craig R J and Wood L E 1970 Effectiveness of corrosion inhibitors and their influence on the physical properties of Portland cement mortars, Highway Research records 328 Highway Research Board

Diamond S 1986 Concentrations in concrete pore solutions resulting from calcium and nitrium chloride admixtures, Cement and concrete aggregates (Philadelphia PA: American Society of Testing and Materials) Vol. 8, pp 97102

Dreeman S, Osroff T, Dillard J, Glanville J and Weyers R 1991 A screening test for rebar corrosion inhibitors (Washington DC: Transportation Research Board)

Gaidis J M and Rosenberg A M 1979 Materials performance (Houston: NACE) Vol. 18 p. 45

Remy H 1961 Inorganic chemistry II (Leipzig: Akademische Verlagsgeselschaft Gest \& Portig) (in German)

Rosenberg A, Grace W R and CO 1993 Mechanism of corrosion of steel in concrete, In Concrete science IV (ed.) J Skalny (Westerville, OH: The American Ceramic Society)

Tashiro C 1984 Effect of zinc oxide admixture on corrosion inhibition of iron in cement mortar containing sea water, Proc 8th int. congress on the chemistry of cement (Rio de Janeiro: Abla Grafica e Editora Ltda) pp 226230

Tashiro C, Takashi H, Kanaya M, Hirakida I and Yosida R 1979 Cement \& Concr. Res. 3283

Tashiro C, Ueoka C and Tashibana K 1985 Effect of heavy metal on corrosion of iron in cement mortar, Proc. SILICONF (Budapest: Magyar Tudomanyos Akademia) pp 281291 